\title{
The Effect of Symmetrical Scaffolding on the Reading Comprehension of Iranian EFL Learners
}

\author{
Somayeh Khajeh Khosravi \\ Department of English, Islamic Azad University of Zahedan, Zahedan, Iran \\ Email address: \\ somayekhosravi12@gmail.com
}

\section{To cite this article:}

Somayeh Khajeh Khosravi. The Effect of Symmetrical Scaffolding on the Reading Comprehension of Iranian EFL Learners. International Journal of Psychological and Brain Sciences. Vol. 2, No. 4, 2017, pp. 95-99. doi: 10.11648/j.ijpbs.20170204.12

Received: May 18, 2017; Accepted: June 1, 2017; Published: July 7, 2017

\begin{abstract}
This study seeks to investigate the impact of symmetrical (S) scaffolding on advance students' reading comprehension. Twenty advance Iranian learners participated in this study. The participants were both male and female students with an average age of 21 . They were taught by symmetrical scaffolding. Before administering a Pre-test was administered to them. At the end of the study, a Post-test was administered, and its results were analyzed through t-test. The results indicated that $\mathrm{S}$ scaffolding has significant effect on learners' performance in reading comprehension.
\end{abstract}

Keywords: Scaffolding, Symmetrical Scaffolding, The Zone of Proximal Development

\section{Introduction}

\subsection{Background}

Reading in second language (L2) settings continues to take on increasing importance... L2 reading ability, particularly with English as the L2, is already in great demand as English continues to spread, not only as a global language but also as the language of science, technology and advanced research. Many people in multilingual settings need to read in an L2 at reasonably high levels of proficiency to achieve personal, occupational and professional goals (Grabe, 2009).

Also, according to Levine, Ferenz, and Reves (2000), "the ability to read academic texts is considered one of the most important skills that university students of English as a second language (ESL) and English as a foreign language (EFL) need to acquire" (p.1). However, as Karasakaloglu (2010) states, "reading action cannot be called reading without comprehending" (p.222).

There are a lot of problems in comprehending an English text. It may have various reasons such as lack of vocabulary, grammatical knowledge, or some psychological problems like fearing failure, lack of motivation... (Magno, 2010). To decrease these problems, recently most of the teachers use various strategies. For example, they try to change the setting of the classrooms from traditional teacher-centered to learner-centered settings (Anton, 1999), or they attempt to use cooperative learning methods in the classroom. To do so, traditional role of a teacher may be replaced by the active role of students via pair or small group work where students are responsible for their own learning. In these small groups, students can learn more by interacting with and teaching to other students (Van Lier, 1996).

Also, as Ohta (2005) states, "the learner is, with assistance, able to outperform what she or he could do without assistance" (p. 507). In recent years, the concept of zone of proximal development (ZPD) has come to be known as one of the cardinal features in learning from a sociocultural perspective. Thus, it has increasingly been applied to second language education. ZPD was first introduced by the Russian psychologist Lev Vygotsky in Thought and Language (1986).

Scaffolding is an umbrella term with widespread ramifications. For example, there are two kinds of scaffolding, namely symmetrical and asymmetrical. In fact, symmetrical scaffolding rests on the fact that learners discover new knowledge through cooperation and interaction. To cast light on symmetrical scaffolding in group work, the following situation is highly probable: student A is good at using a strategy for reading comprehension, while student B is good at vocabulary. Therefore, they can help each other in the course of reading. The striking similarity between symmetrical scaffolding and cooperation is so considerable that some scholars use them interchangeably or prefer to use cooperation as it is more common. Nevertheless, in the present study, the researchers have made a distinction between them: in symmetrical scaffolding 
students cooperate with other students who have similar levels of ZPDs, whereas in cooperation the potential levels of the students are not taken on board (Vygotsky 1986).

As the notions of ZPD and scaffolding are somehow abstract, most of the studies pivoting on them have been conducted on reading and writing skills so as to enhance objectivity. Given that in reading comprehension the interaction among students reaches its zenith, it could be one of the best venues for implementing scaffolding.

\subsection{Statement of Problem}

Reading comprehension is the cornerstone of reading skill (Karasakaloglu, 2010). Many EFL students have a lot of trouble and difficulties in understanding the information presented in the written form of English texts, and sometimes it may be very time consuming for them to read a text in English and understand it.

In reading an English text in the shape of group activity, scaffolding that comes from the students' peers and also sometimes from the classroom's teacher is considered as an utmost important fact.

In spite of increasing students' amount of comprehensible input by applying different scaffolding procedures from the peers in groups, some of the students in those groups fail to interact and negotiate effectively with their peers so their reading comprehension cannot develop efficiently. This is the place that EFL teacher can act as facilitator and provide more language support for students in the groups, and she or he can remove, to some extent, the affective factors and encourage motivation and self - confidence of students. So, the effects of various scaffoldings - that of peer and teacher, in symmetrical groups - such as skimming, scanning, warm-up activities, L1 translation... (Poorahmadi, 2009) and their effects on the reading comprehension development of EFL students in those groups need to be investigated.

\subsection{Significance of Study}

Considering the fact that comprehension is undoubtedly the main goal and an in dispensable part of reading, it is quite important to scrutinize the ways of increasing reading comprehension development. For this reason, teacher labor long and hard and use various strategies in the classrooms to help novice readers to become more proficient. Many of them are aware of the strength of collaborative learning, as a beneficial strategy, in which students are working in groups of two or more to mutually search solutions, understand meanings, or create a product (Goodsell, Maher, Tinto, Smith, \& MacGregor, 1992). So, based on Vygotsky's sociocultural theory (1978) - all learning occurs as a result of social interaction - teachers try to engage students in active learning in small groups.

According to Vygotsky (1934, as cited in Shabani, 2012), "what the child is able to do with some collaboration or assistance today he will be able to do independently tomorrow" (p. 322). However, it is not clear whether there is a significant influence of symmetrical groups on reading comprehension is concerned. Thus, it is worth investigating the theme.

\subsection{Research Question}

This study has focused on question as follows:

Does symmetrical scaffolding have any significant effect on the reading comprehension of Iranian EFL learners?

\subsection{Research Hypothesis}

Based on the above-mentioned research question, the following hypothesis is formulated:

Symmetrical scaffolding have no significant effect on the reading comprehension of Iranian EFL learners.

\section{Literature Review}

\subsection{Scaffolding Guidelines and Features}

Over the decades that the field has been working to clarify instructional scaffolds, a number of general guidelines have been developed. The original notion of scaffolding assumed that a single more knowledgeable person, such as a parent or a teacher, helps individual learners, providing them with exactly the support they need to move forward (e.g., Bruner, 1975; Wood et al.,1976).

One of the most critical aspects of scaffolding is the role of the expert who is knowledgeable about the content of instruction as well as a facilitator with the skills, strategies and processes required for teaching. The expert not only helps motivate learners by providing just enough support to enable them to accomplish the goal, but also provides support in the form of modeling, highlighting the critical features of the task, and providing hints and questions that might help learners to reflect (Wood et al., 1976).

In this conception then, the expert's role has perceptual and cognitive as well as affective components (Stone, 1998).

For Chi (2007) effective scaffolders ought to be sensitive to individual difficulties and decide what to scaffold. To provide more collaborative scaffolding, teachers are highly recommended to ask reflective questions and prompt deep reasoning. Explain as needed: direct instruction is essential and can help students during scaffolding e.g., to explain difficult words or concepts. An effective scaffolder takes students' questions seriously and uses them as material for moving their thinking along.

Larkin (2002) suggests other guidelines for effective scaffolding that teachers shared including the following:

1) Begin with what the students can do. Students need to be aware of their strengths and to feel good about tasks they can do with little or no assistance.

2) Help students achieve success quickly. Although students need challenging work in order to learn, frustration and a "cycle of failure" may set in quickly if students do not experience frequent success.

3) Help students to "be" like everyone else. Students want to be similar to and accepted by their peers. If given the opportunity and support, some students may work harder at 
tasks in order to appear more like their peers.

4) Know when it is time to stop. Practicing is important to help students remember and apply their knowledge, but too much may impede the learning. "Less is more" may be the rule when students have demonstrated that they can perform the task.

5) Help students to be independent when they have command of the activity.

Teachers need to watch for clues from their students that show when and how much teacher assistance is needed. Scaffolding should be removed gradually as students begin to demonstrate mastery and then no longer provided when students can perform the task independently.

The Association for Supervision and Curriculum Development ASCD (2001) provides three guidelines to scaffold effectively:

1) Know your students: Where they are in their current understanding and where you want to take them. The teacher has to know the best way the learner learns best.

2) Have various techniques: Such as note taking aids, manipulative, varied-level readings, learning buddies, graphic organizers, time-management aid, previewing questions (about the next lesson).

3) Monitor students' success. The teacher should get feedback about how things go.

Gibbons (2003) confirms other systems such as visuals, gestures and actions act as agents of scaffolding as they help to mediate learning and they contribute to the creation of 'message abundancy'. The notion of the message being received by the learner in a variety of modes such as oral or written explanations or visual diagrams.

According to van Lier (2004) scaffolding has six central features:

1) Continuity: Tasks are repeated, with variations and connected to one another (e.g. as part of projects).

2) Contextual support: Exploration is encouraged in a safe, supportive environment; access to means and goals is promoted in a variety of ways.

3) Inter subjectivity: Mutual engagement and rapport are established; there is encouragement and nonthreatening participation in a shared community of practice.

4) Contingency: Task procedures are adjusted depending on actions of learners; contributions and utterances are oriented towards each other and may be co constructed.

5) Handover/takeover: There is an increasing role for the learner as skills and confidence increase; the teacher watches carefully for the learner's readiness to take over increasing parts of the action.

6) Flow: Skills and challenges are in balance; participants are focused on the task and are 'in tune' with each other.

In Vygotskian terms, this occurs when the learner has reached internalization. Vygotsky (1978) hypothesized that cognition first occurs between people (inter psychological) before moving to intra psychological (within one's own self). Without fading, this process of internalization cannot happen; students become "prompt-dependent," not independent.

Lipscom, Swanson and West (2004) opine that scaffolding is a natural approach to ensure the learning of the student. The teacher therefore offers assistance with only those skills that are beyond the students' capability.

According to Rodgers \& Rodgers (2004) it is the teacher who decides if help should be given, how much help should be given, the timing of giving the help, and the goal of the instruction. When scaffolding a lesson, teachers must always keep their learners and their ZPD in mind. Teach today's student. A students' ZPD is always changing.

Rodgers (2004) suggests that teachers should provide students with opportunities to make errors. Provoking or noticing these errors provides the teacher with an opportunity to prompt, cue, or explain and model. In doing so, the students and teacher pay joint attention to the task and work together to reach an understanding.

Fisher and Frey (2010) called it "productive failure". However, these errors must be balanced, because too few errors suggest that the task is too easy and scaffolds are not necessary (and thus the student is not working in the zone of proximal development), and too many errors can be "counterproductive to the learning process. (p. 526).

\subsection{Techniques of Scaffolding}

The skillful teacher provides scaffolds that guide, not simply tell, steps back and observes what students do, continuously assesses how well instruction is sticking, and gradually releases responsibility to the student. The use of these scaffolds represents the intersection of the art and the science of teaching (Frey \& Fisher, 2010).

Wood, et al. (1976) name certain processes that aid effective scaffolding:

1. Gaining and maintaining the learner's interest in the task.

2. Making the task simple.

3. Emphasizing certain aspects that will help with the solution.

4. Controlling the child's level of frustration.

5. Demonstrating the task.

Scaffolding is a key feature of effective teaching and can include modeling a skill, providing hints or cues, and adapting material or activity (Copple \& Bredekamp, 2009). Maloch (2002) finds that teacher scaffolds included "direct and indirect explanations and modeling. She suggests a new type of scaffolding, "reconstructive caps" in which the adult highlights the success of the student with the goal of encouraging the student to engage in that behavior or skill again. These reconstructive caps are one more scaffold that adults can use to facilitate student understanding.

Baralt (2013) clarifies that the differences in the types and amounts of scaffolds provided changes depending on the age of the individual providing support, the age of the student receiving the support, and the task itself.

According to Hartman (2002), in the educational setting, scaffolds may include various techniques of support such as models, cues, prompts, hints, partial solutions, think-aloud modeling and direct instruction. Gibbons (2002), moreover, suggests that scaffolding provides high levels of initial, 
deliberate, and well-planned support, and gradually reduces this as students move towards independent control of the learning activity or text. However, it is the teacher's responsibility to watch and decide when and how much support and help is needed; scaffolding can be a moment-to moment help (Davis \& Miyake, 2004).

Silver (2011) mentions four steps for scaffolding instruction which can be performed with just about any task.

1. Assessing the learner's current knowledge and experience.

2. Relating content to what students already understand or can do.

3. Breaking a task into small, more manageable tasks with feedback.

4. Using verbal cues and prompts to assist students.

Fisher and Frey (2010) support four techniques for effective scaffolding.

1) Questioning to check for understanding.

2) Prompting to facilitate students' cognitive and metacognitive processes.

3) Cueing to shift students' attention to focus on specific information, errors, or partial understandings.

4) Explaining and modeling when students do not have sufficient knowledge to complete tasks.

The four points below are excerpted from Ellis and Larkin (1998), as cited in Larkin (2003) and provide a simple structure of scaffolded instruction:

First, the instructor does it: (Teacher does/ student watch) In other words, the instructor models how to perform a new or difficult task, such as how to use a graphic organizer.

Second, the class does it: (Teacher does/ students help) the instructor and students then work together to perform the task. Teacher provides supported practice via prompts and cues to ensure correct performance.

Third, the group does it: (Students do /teacher helps) At this point, students work with a partner or a small cooperative group to complete the task. Cooperative teams perform the skill together, provide the needed support for each other.

Fourth, the individual does it: (Students do/teacher watches) this is the independent practice stage where individual students practice the skill independently without external assistance.

Fisher \& Frey (2013) compared between structures for successful instruction and a structure when learning isn't occurring.

\section{Methods}

\subsection{Participants}

The study was conducted in Privacy Language Institute in
Zahedan, Iran. Twenty advance Iranian EFL learners participated in this study. The participants were both male and female students with an average age of 21 with almost the same educational facilities and physical conditions.

This study was held for twenty four sessions (two months), three days a week and every session lasted for one hour and fifteen minutes.

\subsection{Instruments}

The instruments of this study were:

1) Ten passages from the advanced level of True To Life, five from its workbook, and five from the class-book, were used as the reading texts in this study. Each major level of True To Life has two main books, the class-book and the workbook. During the course of this study, the students were supposed to read the reading comprehension passages in groups. While reading, the students were given feedback by the teacher.

2) Two virtually parallel cloze tests, were developed by the researcher, were served as pre- and post-tests. The reliability of it was calculated.71, using Cronbach's alpha.

\subsection{Procedure and Data Collection}

As mentioned earlier, the participants of the study were in advance classes in Language Institute. A pretest was used at the beginning of the study. During the course of the study, the students were worked on ten reading comprehension passages, five from their workbook and five from their course-book (class-book). While reading, the students were assisted from an implicit to an explicit mode based on the simplified scale of Aljaafreh and Lantolf (1994)'s study. In almost every other session, students were presented with one reading comprehension. Therefore, on the whole, the participants were exposed to 10 reading comprehension passages.

At the end of the treatment period, the cloze post-test, paralleled to the pre-test were taken from advance level of Headway, was administered. Finally, two paired $t$-tests were carried out to compare the performance of participants on pre- and post-tests.

\section{Results}

\subsection{Descriptive Statistics}

Descriptive statistics summarized the characteristics of data including mean, minimum and standard derivation. Table 1 displays the descriptive statistics participants on the pre-test.

Table 1. Descriptive statistics of the participants with regards to reading comprehension.

\begin{tabular}{lllll}
\hline GROUP & NUMBER & MEAN PRE-TEST & SD PRE-TEST & MEAN POST TEST \\
\hline G & 20 & 17.62 & 5.45 & 18.76 \\
\hline
\end{tabular}

As the above table shows, the mean and the standard deviation scores in pretest are respectively 17.62 and 5.45. The mean and the standard deviation scores of the post-test are respectively 18.76 and 5.32 . The comparison of the posttest means showed that participants outperformed on the posttest. So, it can be concluded that symmetrical scaffolding 
has positively affected their scores on the reading comprehension post-test.

\subsection{Research Hypothesis}

To answer the research question, the researchers employed sample paired t-tests. Table 2 indicates the improvement between the pre- and post-tests of the SG.

Table 2. Paired Samples Statistics for SG.

\begin{tabular}{llll}
\hline & N & Mean & standard-Drivation \\
\hline Symmetrical group & 20 & 17.02 & 5.42 \\
\hline
\end{tabular}

The result of the paired t-test showed that there is a significant difference between the two mean scores, $t$ $(38)=4.26, p<.05$. Accordingly, the question addressing the improvement in the symmetrical group was answered in the positive.

\section{Discussion and Conclusions}

\subsection{Discussion}

Q: Does symmetrical scaffolding have any significant effect on the reading comprehension of Iranian EFL learners?

Moreover, the findings did not lend support to Crandall's (1999) idea regarding cooperative groups, which emphasizes the benefit of all students in a group. That is to say, in her opinion both more-able and less-able students almost equally benefit from cooperation. While in this study the homogeneous group outperformed the heterogeneous group, more specifically, the cooperation among the less-able students with more-able students in the heterogeneous group was not as effective as that of the homogeneous group.

Furthermore, Guk and Kellogg (2007) proved the practicality of whole-class scaffolding through teacher-led and student-led interaction. They came to the conclusion that each has its own pros and cons, e.g. teacher-student mediation is The study, however, was, to a large extent, in line with the case study carried out by Nassaji and Swain (2000) in which two female Korean students from among a number of ESL students were selected longer and more accurate than student-student interaction. In a similar vein, the present study supports the viability of whole-class scaffolding raised recently by merely focusing on two types of student interaction.

\subsection{Conclusion}

As the data analysis indicates, the SG participants benefited from reading comprehension. In other words, whenever the students were grouped with other students of similar ZPDs, they were successful. In the SG the students with the similar ZPD were grouped together; therefore, they had a sense of competition, a competition which was fair in that they competed with the students with similar potential knowledge in English reading comprehension.

\subsection{Limitations of the Study}

Like all experimental studies, the present study has some limitations: the scope of the study was narrowed down to include only EFL advance learners who were at private institute in Zahedan.

This study was restricted to advance level due to class availability and supervisor's permission.

Certain limitations of this study related to selection of participants. The participants were both male and female students with an average age of 21. All of they spoke Persian as their first language and English as the second one.

Another limitation was participant's unwillingness to take part in this study. In addition, since this study needed to be conducted as a component of regularly scheduled EFL classes, it was impossible to follow the standard procedure to randomly select participants during class meeting time.

These participants have been teaching English in private institutes and not academic context.

\section{References}

[1] Gibbons, P. (2002). Scaffolding language, scaffolding learning.

[2] Grabe, W. (2009). Reading in a second language: Moving from theory to practice. Ernst Klett Sprachen.

[3] Hammond, J., \& Gibbons, P. (2005). Putting scaffolding to work: The contribution of scaffolding in articulating ESL education.

[4] Khodamoradi, A., Iravani, H., \& Jafarigohar, M. (2013). The Effect of Teacher's Scaffolding and Peers' Collaborative Dialogue on the Acquisition of English Tenses in the Zone of Proximal Development: A Sociocultural Perspective. European Online Journal of Natural and Social Sciences, 2 (2s), 336.

[5] Magno, C. (2010). The effect of scaffolding on children's reading speed, reading anxiety, and reading proficiency. TESOL Journal, 3, 92-98.

[6] Nassaji, H., \& Swain, M. (2000). A Vygotskian perspective on corrective feedback in L2: The effect of random versus negotiated help on the learning of English articles. Language awareness, 9 (1), 34-51.

[7] Poorahmadi, M. (2010). The effect of employing scaffolding strategies and classroom tasks in teaching reading comprehension. The Journal of TEFLL, 1(3).

[8] Quintana, C., Reiser, B. J., Davis, E. A., Krajcik, J., Fretz, E., Duncan, R. G.,... \& Soloway, E. (2004). A scaffolding design framework for software to support science inquiry. The journal of the learning sciences, 13 (3), 337-386.

[9] Sharpe, T. (2006). 'Unpacking'scaffolding: Identifying discourse and multimodal strategies that support learning. Language and Education, 20 (3), 211-231.

[10] Szymańska, A., \& Kaczmarek, A. W. (2011). Reading efficiency in blended learning context. Teaching English with technology, 11(2), 29-42. 